\title{
Oral Microencapsulated Diindolylmethane
}

\author{
National Cancer Institute
}

\section{Source}

National Cancer Institute. Oral Microencapsulated Diindolylmethane. NCI Thesaurus. Code C71132.

An orally bioavailable microencapsulated formulation of diindolylmethane, an indole phytonutrient found in cruciferous vegetables, with estrogen-modulating, antiandrogenic, and potential antineoplastic activities. As a dimer of indole-3-carbinol, diindolylmethane (DIM) modulates estrogen balance by reducing the levels of 16-hydroxy estrogen metabolites and increasing the formation of beneficial 2-hydroxy estrogen metabolites. DIM also antagonizes androgen receptor activity, which may result in diminished cell proliferation and apoptosis in susceptible tumor cell populations. Pure DIM, which is relatively hydrophobic, is poorly absorbed after oral administration. This oral formulation, which consists of DIM, d-alpha-tocopheryl acid succinate, phosphatidylcholine, and silica microencapsulated in starch, significantly improves the gastrointestinal absorption of DIM. 